\title{
PREVALÊNCIA E PERFIL DE SENSIBILIDADE BACTERIANA EM ÉGUAS COM ENDOMETRITE
}

\section{$\underline{\text { Tatiana Cabrera}^{1},}$, Marília Pastorello², Marco Antonio Alvarenga ${ }^{3}$}

1 Doutoranda em Biotecnologia Animal pela Universidade Estadual Paulista "Júlio de Mesquita Filho" UNESP (medvetunesp@gmail.com) Botucatu- SP, Brasil

2 Médica Veterinária, Central de Reprodução Equina Genetic Jump, ItapetiningaSP, Brasil

3 Professor Adjunto do Departamento de Reprodução Animal e Radiologia Veterinária, Universidade Estadual Paulista "Júlio de Mesquita Filho" UNESP

Botucatu-SP, Brasil

Recebido em: 08/04/2016 - Aprovado em: 30/05/2016 - Publicado em: 20/06/2016 DOI: 10.18677/Enciclopedia_Biosfera_2016_087

A endometrite é uma das principais afecções da fêmea equina que acarreta prejuízos financeiros nos programas de transferência de embrião. Terapias a base de antimicrobianos são muitas vezes administradas, principalmente por profissionais que trabalham a campo, sem uma prévia realização de técnicas de diagnóstico como cultura uterina e antibiograma. O presente estudo teve como objetivo estudar a predominância de bactérias isoladas dos úteros das éguas e a sensibilidade desses micro-organismos frente a diferentes antibióticos. Foram realizadas 196 culturas uterinas em éguas de diferentes raças, entre cinco e 20 anos de idade. Desse total de culturas, 140 foram positivas para uma ou mais bactérias e apresentaram a seguinte prevalência: $64(45,7 \%)$ para Escherichia colli; 31(22,1\%) para Staphylococcus aureus, 21(15\%) para Staphylococcus epidermicus, 14(10\%) para Staphylococcus saprophyticus, $11(7,8 \%)$ para Klebsiella pneumoniae; 7 (5,0\%) para Pseudomonas sp; 6 (4,2\%) para Streptococcus $\alpha$-hemolítico e Proteus vulgaris; 4 (2,9\%) para Citrobacter sp e $1(0,7 \%)$ para Edwardsiella, Enterobacter aerogenes, Yersinia e Alcaligenes. Dos antibiogramas realizados, 66,4\%; 55,7\%; 41,4\%; 30,0\%; $10 \% ; 9,3 \% ; 2,9 \%$ e $0,7 \%$ foram sensíveis para enrofloxacina, amicacina, gentamicina, sulfa/trimetoprim, ampicilina, ceftiofur e tobramicina, cloranfenicol, respectivamente. No presente estudo, conclui-se que a bactéria mais frequentemente isolada foi a Escherichia colli seguida por Staphylococcus aureus e a enrofloxacina mostrou ser 0 antibiótico a apresentar maior sensibilidade antimicrobiana.

PALAVRAS-CHAVE: antibiótico, cultura bacteriológica, infecção uterina. 


\title{
PREVALENCE AND PROFILE OF BACTERIAL SENSITIVITY IN MARES WITH ENDOMETRITIS
}

\begin{abstract}
The endometritis is one of the main diseases of the equine female entails financial losses in embryo transfer programs. Antimicrobial therapies are often administered mainly by professionals working in the field, without a prior execution of diagnostic techniques such as uterine culture and sensitivity. This experiment aimed to study the prevalence of bacteria isolated from the wombs of mares and the sensitivity of these microorganisms in comparison to different antibiotics. 196 uterine cultures were performed in mares of different breeds, between five and 20 years of age. Of this total cultures, 140 were positive for one or more bacteria and showed the following prevalence: 64 (45.7\%) Escherichia colli; 31 (22.1\%) Staphylococcus aureus; 21 (15\%) Staphylococcus epidermicus, 14 (10\%) Staphylococcus saprophyticus; 11 (7.8\%) Klebsiella pneumoniae; 7 (5.0\%) Pseudomonas sp; 6 (4.2\%) a-hemolytic Streptococcus and Proteus vulgaris; 4 (2.9\%) Citrobacter $s p$ and $1(0.7 \%)$ Edwardsiella, Enterobacter aerogenes, Alcaligenes and Yersinia. Of the antibiograms performed $66.4 \%$; $55.7 \%$; $41.4 \%$; 30.0\%; 10\%; 9.3\%; $2.9 \%$ and $0.7 \%$ were sensitive to enrofloxacin, amikacin, gentamicin, sulfa/trimethoprim, ampicillin, ceftiofur and tobramycin, chloramphenicol, respectively. In the present study, it was concluded that the most frequent bacterium Escherichia colli was followed by Staphylococcus aureus and enrofloxacin was found to be the antibiotic to have higher antimicrobial susceptibility.
\end{abstract}

KEYWORDS: antibiotic, bacterial culture, uterine infection.

\section{INTRODUÇÃO}

$\mathrm{Na}$ reprodução equina, a endometrite é uma das principais causas de infertilidade. A contaminação do aparelho reprodutivo por micro-organismos, particularmente os de origem bacteriana são em sua maior parte, considerados agentes patogênicos oportunistas e podem ser introduzidos de várias formas (WITTENBRINK, 2012).

Logo após o parto, a abertura da cérvix permite a passagem de microorganismos da vagina para o útero, como o lóquio, que constitui um rico substrato para a multiplicação de patógenos. Outras condições que permitem que bactérias se estabeleçam no trato genital incluem má conformação perineal; monta natural, inseminações artificiais com pouca higiene; irritações repetidas e 0 uso indiscriminado de antibióticos (DAVIS et al., 2013; BENKO et al., 2015). Endometrites subclínicas geralmente não apresentam sintomas, como acúmulo de fluido no útero, o que dificulta o diagnóstico (LEBLANC \& CAUSEY, 2009).

$\mathrm{O}$ isolamento bacteriológico e os testes de sensibilidade são processos que demandam tempo e custo. Durante a estação de monta, a necessidade de um tratamento rápido faz com que muitos profissionais a campo escolham o antibiótico baseado em protocolos pré-estabelecidos sem a realização de exames diagnósticos, como citologia, cultura uterina e antibiograma (AL-HUMAN, 2015).

Segundo STERNBERG (1999), há uma constante variação nas espécies de bactérias isoladas, bem como na susceptibilidade aos antibióticos que podem variar de uma população para outra. Uma antibioticoterapia inadequada pode resultar em falhas no tratamento e consequentemente perdas econômicas (PYORALA et al., 2014). 
Embora não se conheça exatamente o mecanismo, o uso repetitivo, prolongado e excessivo de antimicrobianos parece estar associado ao aumento da incidência de endometrites fúngicas (LIU, 2011). Segundo COUTINHO DA SILVA \& ALVARENGA (2011) o refluxo de antibióticos e desinfetantes usados repetidas vezes nos tratamentos uterinos pode modificar a flora vaginal e criar um ambiente propício para o desenvolvimento de agentes patogênicos como fungos.

O objetivo deste estudo foi verificar a prevalência dos micro-organismos na cultura uterina e sua sensibilidade antimicrobiana em éguas com problemas de fertilidade.

\section{MATERIAL E MÉTODOS}

Esse estudo foi aprovado pela comissão de ética da Faculdade de Medicina Veterinária e Zootecnia - UNESP/Botucatu com protocolo número 11/2016. Durante a estação de monta foram coletados material uterino de 196 éguas matrizes e doadoras de embrião de diferentes raças com idade entre cinco e 20 anos com suspeita de endometrite.

A seleção foi baseada no histórico reprodutivo de éguas que não ficaram gestantes ou apresentaram lavados negativos para coleta de embriões na estação de monta anterior e que apresentaram processo inflamatório uterino detectado ao exame citológico.

Todas as éguas foram examinadas através de palpação retal e ultrassonografia transuterina (ultra som ALOKA 210 transdutor linear frequência de 5 Mhz) para determinação da fase do ciclo estral. A coleta da secreção uterina foi realizada nos animais durante o estro. Após antissepsia da vulva e períneo, os swabs estéreis com meio de transporte Stuart (ABSORVE® - Cotia - SP) protegidos e acoplados em uma haste de metal inoxidável, eram introduzidos pela vagina até a entrada da cérvix no qual se coletava a amostra no interior do útero (ALVARENGA \& MATTOS, 1990). Após a coleta, os swabs foram imediatamente acondicionados, fechados e identificados para serem enviados em até oito horas para laboratório em temperatura ambiente.

A cultura do material foi realizada em meios de ágar base acrescido de $8 \%$ sangue ovino desfibrinado e ágar MacConkey. Posteriormente as amostras foram incubadas sob condições anaeróbicas a $37^{\circ} \mathrm{C}$ e observadas em 24,48 e 72 horas (KONEMAN, 2001).

Os testes de sensibilidade antimicrobiana foram realizados utilizando-se a técnica de difusão de disco em ágar Mueller Hinton segundo BAUER et al., (1966). Foram utilizados os seguintes antibióticos: enrofloxacina, amicacina, ampicilina gentamicina, sulfa e trimetroprim, ceftiofur, cloranfenicol, tobramicina e penicilina.

Os resultados foram tabulados em planilha do Excelß e estatísticas descritivas foram produzidas, considerando a frequência de cada espécie de microorganismo isolada, além da susceptibilidade ou resistência aos antibióticos testados. Os resultados foram expressos em porcentagem.

\section{RESULTADOS E DISCUSSÃO}

O presente estudo mostrou que $71,4 \%$ das éguas com problemas de fertilidade estavam com processo de endometrite bacteriana. Das 196 culturas realizadas, 140 foram positivas para um ou mais micro-organismos. As bactérias isoladas do útero de éguas neste trabalho foram similares ao que é reportado pela 
literatura. Entretanto, foi observado uma diferença em relação à frequência de isolamento desses micro-organismos.

As bactérias mais frequentemente isoladas no presente experimento foram Escherichia colli $(45,7 \%)$, seguidas por Staphylococcus aureus $(22,1 \%)$. Os resultados do exame microbiológico podem ser observados na tabela 1.

TABELA 1 - Bactérias isoladas nas 140 culturas uterinas positivas.

\begin{tabular}{lcc}
\hline MICRO-ORGANISMOS & FREQUÊNCIA & PERCENTUAL \\
\hline Escherichia coli & 64 & 45,7 \\
Staphylococcus aureus & 31 & 22,1 \\
Staphylococcus epidermicus & 21 & 15,0 \\
Staphylococcus saprofit & 14 & 10,0 \\
Klebsiella sp & 11 & 7,8 \\
Pseudomonas sp & 7 & 5,0 \\
Streptococcus a-hemolítico & 6 & 4,2 \\
Proteus sp & 6 & 4,2 \\
Citrobacter sp & 4 & 2,9 \\
Enterobacter aerogenes & 1 & 0,7 \\
Edwardsiella & 1 & 0,7 \\
Alcaligenes faecalis & 1 & 0,7 \\
Yersinia sp & 1 & 0,7 \\
\hline
\end{tabular}

OLIVEIRA et al., (2010) também relataram em éguas uma maior ocorrência de Escherichia coli. Porém, seguido por klebsiella sp e Shigela sp. Na espécie canina, VOLPATO et al., (2014) também assinalaram a bactéria Escherichia colli como a mais frequente na etiologia de animais com piometra.

De acordo com MCKINNON (2010), as bactérias Escherichia colli, Klebsiella $\mathrm{sp}$, Staphylococcus sp, Streptococcus $\beta$-hemolítco e Corynebacterium também são frequentemente isoladas no sêmen, uretra e prepúcio de garanhões. Segundo MARTH et al., (2015) a Escherichia colli se prolifera rapidamente, com formação em 20 minutos; sendo necessário, portanto, uma rápida resposta imune para a contenção da infecção.

A frequência de isolamento dos micro-organismos Streptococcus $\alpha$ hemolítico foi de 4,2\%. Diferente dos resultados do presente experimento, outros autores apontam o Streptococcus $\beta$-hemolítico como a bactéria patogênica mais frequentemente isolada (PROIETTI et al., 2011, CÂMARA et al., 2013; BUCZKOWSKA et al., 2014).

LANGONI et al., (1994) em estudo com 445 culturas uterinas de éguas também verificaram a incidência em primeiro lugar do micro-organismo Streptococcus sp (S. zooepidemicus, S.equisimilis, S.faecalis e S.equi) em aproximadamente $40 \%$; seguido por Staphylococcus sp $(23,5 \%)$ e Escherichia coli $(12,3 \%)$.

Em estudo realizado com 7665 éguas com suspeita de endometrite, as bactérias isoladas com maior frequência foram Escherichia colli, Streptococcus equi subsp zooepidemicus e Enterobacteriaceae sp (DAVIS et al., 2013). Os autores citam que a variabilidade dessas bactérias pode ser atribuída às amostras das populações de éguas, como também à localização geográfica e exposição desses animais aos vários antimicrobianos. 
Os resultados referentes a sensibilidade das bactérias frente aos antibióticos testados in vitro estão nas tabelas 2 e 3.

TABELA 2 - Perfil de sensibilidade microbiana das amostras de bactérias isoladas do conteúdo uterino de éguas

\section{SENSÍVEL}

\begin{tabular}{lcc}
\hline ANTIBIÓTICO & FREQUENNCIA & PERCENTUAL \\
\hline Enrofloxacina & 93 & 66,4 \\
Amicacina & 78 & 55,7 \\
Gentamicina & 58 & 41,4 \\
Sulfa eTrimetroprim & 42 & 30,0 \\
Ampicilina & 14 & 10,0 \\
Ceftiofur & 13 & 9,3 \\
Penicilina & 4 & 2,9 \\
Trobamicina & 4 & 2,9 \\
Cloranfenicol & 1 & 0,7 \\
\hline
\end{tabular}

TABELA 3 - Sensibilidade microbiana in vitro do conteúdo uterinos de éguas com endometrite frente aos antibióticos (\%)

\begin{tabular}{|c|c|c|c|c|c|c|c|c|c|c|}
\hline & ANTI & BIÓTI & $\cos$ & & & & & & & \\
\hline MICRO-ORGANISMOS & ENR & AMI & GEN & SUL & AMP & CEF & PEN & TRO & CLO & RES \\
\hline Escherichia coli & 64,1 & 66,7 & 43,9 & 38,6 & 8,8 & 3,5 & - & 3,5 & 1,7 & - \\
\hline Staphylococcus Aureus & 80,6 & 67,7 & 41,9 & 19,3 & 9,7 & 16,1 & - & - & - & - \\
\hline $\begin{array}{l}\text { Staphylococcus } \\
\text { Epidermicus }\end{array}$ & 64,3 & 57,1 & 64,3 & 35,7 & 14,3 & - & - & - & - & - \\
\hline Staphylococcus Saprofit & 100 & 42,9 & 57,1 & 42,9 & - & - & - & - & - & - \\
\hline Klebsiella sp & 66,7 & 22,2 & 0 & 22,2 & - & 33,3 & - & - & - & - \\
\hline Pseudomonas sp & 42,9 & 42,9 & 28,6 & - & - & - & - & - & - & 11,1 \\
\hline Streptococcus sp & 50,0 & 33,3 & 16,7 & 33,3 & - & - & 33,3 & - & - & - \\
\hline Proteus sp & 16,7 & 33,3 & 50,0 & 33,3 & - & 33,3 & - & 16,7 & - & - \\
\hline Citrobacter sp & 100 & 66,6 & 66,6 & 33,3 & - & - & - & - & - & - \\
\hline Enterobacter aerogenes & 100 & 100 & 100 & - & - & - & - & - & - & - \\
\hline Edwardsiella & - & - & 100 & - & - & - & - & - & - & - \\
\hline Alcaligenes faecalis & 100 & 100 & 100 & - & - & - & - & - & - & - \\
\hline
\end{tabular}


Dos antibióticos estudados a enrofloxacina foi o antibiótico a apresentar maior sensibilidade antimicrobiana para a maioria das bactérias. Estes resultados corroboram com a literatura existente (CÂMARA et al., 2013; BENKO et al., 2015). Outro antibiótico a apresentar alta sensibilidade antimicrobiana foi a amicacina, principalmente para a Escherichia colli. Em estudo com humanos, SILVA et al., (2014) também referiram a susceptibilidade da E. coli para amicacina $(96,8 \%)$ de material proveniente de urocultura de gestantes.

Segundo WITTENBRINK (2012), muitas cepas da Pseudomonas aeruginosa produzem exotoxina $A$ que causa necrose tecidual devido ao bloqueio da síntese de proteínas das células hospedeiras. Estas e outras pseudomonas apresentam alta resistência a vários agentes antimicrobianos, coincidindo com os resultados do presente estudo. GONCAGUL \& SEYREK-INTAS (2013) observaram alta sensibilidade da Escherichia colli aos antimicrobianos enrofloxacina e sulfatrimetoprim. No entanto, a $100 \%$ das cepas foram resistentes à penicilina.

Diferentes respostas inflamatórias uterinas são dependentes dos tipos de patógenos causadores de endometrite. Bactérias como a Escherichia colli e o Streptococccus tendem a se aderir nas superfícies epiteliais impedindo sua remoção física e a estimular a produção de exsudato inflamatório (BUCZKOWSKA et al., 2015). Esses micro-organismos têm a capacidade de formar biofilmes, tornando-se resistentes aos antibióticos e consequentemente gerando infecções crônicas (LEBLANC, 2010). Segundo PYORALA et al., (2014), lavagens uterinas devem ser realizadas antes do uso do antimicrobiano, a fim de remover algum tipo de conteúdo uterino que pode inativar ou ainda diluir o antibiótico.

DAVIS et al., (2013) observaram em estudo que, com o decorrer dos anos, os resultados dos antibiogramas mostraram que a bactéria Escherichia coli diminuiu significativamente a resistência para polimixina $B$, provavelmente devido ao baixo uso desse antibiótico na prática. Por outro lado, a resistência dos antimicrobianos ampicilina, enrofloxacina, gentamicina, sulfa e trimetroprim e ticarilin aumentou devido a maior utilização intra uterina ou sistêmica, nos casos de placentite. De acordo com GONZALEZ et al., (2009), variações nas atividades antimicrobianas podem ocorrer mesmo em fármacos de uma mesma família.

\section{CONCLUSÕES}

No presente estudo, conclui-se que a bactéria mais frequentemente isolada do material uterino de éguas foi a Escherichia colli seguido por Staphylococcus aureus e a enrofloxacina mostrou ser o antibiótico a apresentar maior sensibilidade antimicrobiana. A utilização da cultura uterina associada ao antibiograma contribui para o estabelecimento de um protocolo terapêutico seguro e adequado para éguas com endometrite bacteriana.

\section{REFERÊNCIAS}

AL-HUMAM, N.A. Etiology and bacterial antimicrobial susceptibility of endometritis in camels (Camelus dromedarius). British Journal of Applied Science \& Technology, v.13, n.1, p.1-6, 2015. Disponível em: <http://dx.doi.org/10.9734/BJAST/2016/22019>. Acesso em: 10 dez. 2015.

ALVARENGA, M.A.; MATTOS, M.C.F.I. Eficiência da escova ginecológica "cytobrush" na colheita de material endometrial de éguas. Arquivo Brasileiro de Medicina Veterinária e Zootecnia, v.42, n.1, p.67-68, 1990. Disponível em: < 
http://cpro4576.publiccloud.com.br:8080/editoraconsulta/artigo/exibir/exibirArtigo.do? codigo=5535> $>$. Acesso em: 10 fev. 2016.

BAUER, A.W.; KIRBY, W.M.M.; SHERRIS, J.C. Antibiotic susceptibility testing by a standardized single disk method. American Journal of Clinical Pathology, v. 45, p.493-496, 1966.

Disponivel em:<http://202.114.65.51/fzjx/wsw/newindex/wswfzjs/pdf/105bauer.pdf>. Acesso em: 25 nov. 2015.

BENKO, T.; BOLDIZAR, M.; NOVOTNY, F.; HURA, V.; VALOCKY, I.; DUDDRIKOVA, K.; KARAMANOVA, M.; PETROVIC, V. Incidence of bacterial pathogens in equine uterine swabs, their antibiotic resistance patterns, and selected reproductive índices in English thoroughbred mares during the foal heat cycle. Veterinarni Medicina, v. 60, n.11, p.613-620, 2015. Disponível em:<http://dx.doi.org/10.17221/8529-VETMED>. Acessso em: 7 jan. 2016.

BUCZKOWSKA, J.; KOZDROWSKI, R.; NOWAK, M.; RÁS, A.; STARONEWICZ, Z.; SIEMIENIUCH, J.M. Comparison of the biopsy and cytobrush techniques for diagnosis of sublinical endometritis in mares. Reproduction, Biology and Endocrinology, v.12, n.27, 2014. Disponível em: <http://dx.doi.org/10.1186/14777827-12-27>. Acesso em: 21 nov. 2015.

BUCZKOWSKA, J.; KOZDROWSKI, R.; SIKORA, M.; DZIECIOL, M.; MATUSZ, A. Non-traditional treatments for endometritis in mares. Bulgarian Journal of Veterinary Medicine, 2015. Disponível em : < http://dx.doi.org/10.15547/bjvm 870>. Acesso em: 5 jan. 2016.

CÂMARA, W.M.; CANCIMANSI, J.A.N.; SHIMODA, E.; FAGUNDES, B.; BARRETO, M.A.P.; SILVA, J.F.S. Identificação e perfil de sensibilidade antimicrobiana de bactérias isolada de éguas suspeitas ou não de endometrite. Agrária- Revista Brasileira de Ciências Agrárias, v.8, n.4, p.669-674, 2013. Disponível em: <http://dx.doi.org/10.5039/agraria.v8i4a2534>. Acesso em: 2 dez. 2015.

COUTINHO DA SILVA, M.A.; ALVARENGA, M.A. Fungal endometritis in mares. In: MCKINNON, A.O.; SQUIRES, E.L.; VAALA, W.E.; VARNER, D.D. Equine Reproduction. Nova lorque: Wiley-Blackwell, p.2532-2538.2011.

DAVIS, H.A.; STATON, M.B.; THUNGRAT, K.; BOOTHE, D.M. uterine bacterial isolates from mares and their resistance to antimicrobials: 8,296 cases (2003-2008). Journal of the American Veterinary Medical Association, v. 242, n. 7, p. 977-983, 2013. Disponível em: <http://dx.doi.org/10.2460/javma.242.7.977>. Acesso em: 5 dez. 2015.

GONCACUL, G.; SEYREK-INTAS, K. Antimicrobial susceptibility of bacteria isolated from uteri of thoroughbred mares with fertility problems. Kafkas Universitesi Veteriner Fakultesi Dergisi, v.19, n.3, 2013. Disponível em:<http://dx.doi.org/10.9775/kvfd.2012.8094>. Acesso em: 27 nov. 2015.

GONZALEZ, C.; MORENO, L.; FUMUSO, E.; GARCÍA, J.; RIVULGO, M.; CONFALONIERI, A.; SPARO, M.; SÁNCHEZ, B.S. Enrofloxacin-based therapeutic in susceptible mares. Journal of Veterinary Pharmacology and Therapeutics, v.33, 
n.3, p.287-294, 2009. Disponível em: <http://dx.doi.org/10.1111/j13652885.2009.01135.x>. Acesso em: 27 nov. 2015.

KONEMAN, E.W. Diagnóstico Microbiológico- Texto e Atlas Colorido. 5. Ed. Rio de Janeiro: MEDSI Editora Médica e Científica LTDA, cap.3, p.125-67.2001.

LANGONI, H.; ALVARENGA, M.A.; PAPA, F.O.; SAKAMOTO, C.; SIMON, J.J.; LISTONI, F.J.P.; CARREIRA, E.L.C. Estudo microbiológico e citológico do trato genital de éguas. Arquivo Brasileiro de Medicina Veterinária e Zootecnia, v.46, n.6, p.623-636, 1994. Disponível em: http://cpro4576.publiccloud.com.br:8080/editora//upload/trabalho/v46/v46n6a3.pdf >.

Acesso em: 31 jan. 2016.

LEBLANC, M.M. Advances in the diagnosis and treatment of chronic infections and post-mating-induced endometritis in the mare. Reproduction in Domestic Animals, v.45, p.21-27, 2010. Disponível em: <http://dx.doi.org/10.1111/j.14390531.2010.01634.x>. Acesso em: 5 jan. 2016.

LEBLANC, M.M.; CAUSEY, R.C. Clinical and subclinical endometritis in the mare: both threats to fertility. Reproduction Domestic Animal, v.44, p.10-22, 2009. Disponível em: <http://dx.doi.org/10.1111/j.1439-0531.2009.01485.x>. Acesso em: 5 jan. 2016.

LIU, I.K.M. The diagnosis, causes and treatment of persistent endometritis in the mare. Revista Brasileira de Reprodução Animal, v.35, n.2, p.256-261, 2011. Disponível em: http://www.cbra.org.br/pages/publicacoes/rbra/v35n2/RB382\%20Liu\%20pag256261.pdf>. Acesso em: 10 fev. 2016.

MARTH, C.D.; YOING, N.D.; GLENTON, L.Y.; NODEN, D.M.; BROWNING, G.F.; KREKELER, N. Deep sequencing of the uterine immune response to bacteria during the equine oestrous cycle. BMC Genomics, v.16, p.934, 2015. Disponível em: http://dx.doi.org/10.1186/s12864-015-2139-3>. Acesso em: 4 jan. 2016.

MCKINNON, A.O. Reprodução da égua problema. In: CONFERÊNCIA ANUAL DA ASSOCIAÇÃO BRASILEIRA DOS MÉDICOS VETERINÁRIOS, v.11, 2010, São Paulo. Anais... São Paulo: ABRAVEQ, 2010. Disponível em: $<$ http://www.itarget.com.br/newclients/abraveq2015/down/2015/conf sp equa proble ma.pdf $>$. Acesso em: 29 nov. 2015.

OLIVEIRA, I.B.; PEIXOTO, R.M.; SILVA, D.R.; PINHEIRO JUNIOR, J.W.; OLIVEIRA, A.A.F.; MOTA, R.A. Análise comparativa entre o exame citológico e microbiológico no diagnóstico de endometrite equina. Veterinária e Zootecnia, v.17, n.1, p.43-46, 2010. Disponível em: <http://www.fmvz.unesp.br/rvz/article/279/224>. Acesso em: 8 dez. 2015.

PROIETTI, P.C.; BIETTA, A.; COPPOLA, G.; FELICETTI, M.; COOK, R.F.; COLLETI, M.; MARENZONI, M.L.; PASSAMONTI, F. Isolation and characterization of $\beta$-haemolytic-Streptococi from endometritis in mares. Veterinarinary Microbiology, v.152, p.126-130, 2011. Disponível em: <http://dx.doi.org/ 10.11016/j.vetmic.2011.04.009>. Acesso em: 5 dez. 2015. 
PYORALA, S.; TAPONEN, J.; KATILA, T. Use of antimicrobials in the treatment of reproductive diseases in cattle and horses. Reproduction in Domestic Animals, v.49, n.Supplements.3, p.16-26, 2014. Disponível em: <http://dx.doi.org/10.1111/rda.12324>. Acesso em: 29 dez. 2015.

SILVA, L.M.; MACEDO, C.F.C.; VASCONCELOS, D.P.; GOMIDES, M.D.A.; SADOYAMA, G. Escherichia coli isoladas de infecção urinária em gestantes: Perfil de resistência aos antimicrobianos. Enciclopédia Biosfera, Centro Científico Conhecer- Goiânia, v. 10, n. 19, p. 233, 2014. Disponível em:< http://www.conhecer.org.br/enciclop/seminario/Escherichia.pdf>. Acesso em: $10 \mathrm{dez}$. 2015.

STERNBERG, S. Antimicrobial resistance in bacteria from pets and horses. Acta Veterinaria Scandinavica. Suppl. v.92, p.37-50, 1999.

VOLPATO, R.; ARAUJO, M.S.; TSUNEMI, M.H.; LISTONI, F.J.P.; RIBEIRO, M.G.; LOPES, M.D. Caracterização microbiológica e perfil de resistência das bactérias isoladas do útero de cadelas com piometra aberta e fechada. Revista Portuguesa de Ciências Veterinárias, v. 109, 591-592, p. 100-104, 2014. Disponível em: http://www.fmv.ulisboa.pt/spcv/edicao/12 2014/100-104.htm>. Acesso em: $12 \mathrm{dez}$. 2015.

WITTENBRINK, M.M. Bacterial infections of the equine genital tract. Pferdehellkunde, 28, p.30-32, 2012. Disponível em:<http://dx.doi.org/10.5167/uzh61077 >. Acesso em: 20 dez. 2015. 